\title{
Molecular data and species diagnosis in Essigella Del Guercio, 1909 (Sternorrhyncha, Aphididae, Lachninae)
}

\author{
Thomas Théry', Mariusz Kanturski², Colin Favret' \\ I University of Montreal, Department of Biological Sciences, Biodiversity Centre, 4101 E. Sherbrooke Street, \\ Montreal QC, H1X 2B2 Canada 2 Department of Zoology, Faculty of Biology and Environmental Protection, \\ University of Silesia in Katowice, Bankowa 9, 40-007 Katowice, Poland
}

Corresponding author: Thomas Théry (thomasjcthery@gmail.com)

Academic editor: R. Blackman | Received 31 January 2018 | Accepted 28 April 2018 | Published 7 June 2018

http://zoobank.org/BD00760D-C946-4110-8C86-8CA2872C7CE3

Citation: Théry T, Kanturski M, Favret C (2018) Molecular data and species diagnosis in Essigella Del Guercio, 1909 (Sternorrhyncha, Aphididae, Lachninae). ZooKeys 765: 103-122. https://doi.org/10.3897/zookeys.765.24144

\begin{abstract}
Morphological and molecular data are used to describe three new species of Essigella (Sternorrhyncha: Aphididae: Lachninae): Essigella domenechi sp. n., Essigella gagnonae sp. n., and Essigella sorenseni sp. n.; and to re-establish as valid Essigella patchae Hottes, 1957, stat. n., until now considered a synonym of $E$. pini Wilson, 1919. The catalogue of Essigella species is updated. This study highlights the need and utility to use discreet DNA characters in aphid species diagnoses.
\end{abstract}

\section{Keywords}

Cryptic species, DNA sequences, Hemiptera, taxonomy

\section{Introduction}

Morphological characters remain the commonest way to separate animal species, and they are conspicuously used in diagnoses and descriptions of new taxa. However, in the case of cryptic species, no or few morphological differences are available, and other kinds of taxon-related attributes must be employed as valuable diagnostic characters. DNA sequences permit the discovery of cryptic species and are used to separate them from their relatives (Hebert et al. 2003a, b, Cœur d'acier et al. 2014, Lukhtanov and Dantchenko 2017, Morinière et al. 2017). However, despite their reliability, they are seldom used 
specifically in diagnoses of new species, notably because they are not specifically recommended in the International Code of Zoological Nomenclature (Renner 2016).

Essigella (Sternorrhyncha: Aphididae: Lachninae) is an aphid genus found on the needles of various pinaceous hosts. Most species feed on true pines, Pinus Linnaeus, but E. wilsoni Hottes, 1957, is found only on Douglas firs, Pseudotsuga Carrière. Essigella alyeska Sorensen, 1988 is recorded on spruce, Picea A. Dietrich, although its typical host is Pinus banksiana Lamb. (Sorensen 1994). Most species of Essigella are considered monophagous except E. californica (Essig, 1909) and E. pini Wilson, 1919 which are oligophagous on Pinus (Sorensen 1994). Although all species are Nearctic in origin, E. californica was accidently introduced in several countries around the world (Théry et al. 2017). Essigella currently encompasses 15 valid taxa, with an additional 13 synonyms (Wilson 1919, Gillette and Palmer 1924, Hottes 1957, 1958, Sorensen 1988, 1994). Species are variable and show few diagnostic characters (Sorensen 1994). The genus was revised by Sorensen (1994) using morphometric data and multivariate analyses. Besides the 15 taxa he recognized, Sorensen (1994) notably divided Essigella into three subgenera: Archeoessigella, Essigella and Lambersella, two species series, and three species complexes. A recent molecular phylogenetic study did not support the validity of the three subgenera and of one of the species series (Théry et al. in press). Moreover, the phylogenetic results, combined with molecular species delimitation methods, revealed that two species, Essigella californica and E. pini, actually encompass four and two species, respectively. In the case of $E$. pini, one of the two species is suspected to be $E$. patchae Hottes, 1957, considered a synonym of E. pini by Sorensen (1994). Examination of type material of E. californica and E. pini, as well as that of their respective synonyms and reference specimens, indicates that the three cryptic species found within $E$. californica are new to science and confirms the validity of E. patchae.

In the present work, we describe as new the three cryptic species revealed by Théry et al. (in press): Essigella domenechi sp. n., E. gagnonae sp. n. and E. sorenseni sp. n. In addition, we re-establish $E$. patchae stat. n. and provide diagnostic characters to separate it and E. pini. Because these four species are difficult to distinguish morphologically, discreet DNA sequence data supplement classical morphological characters in the diagnoses.

\section{Materials and methods}

\section{Abbreviations used}

CTT Private Collection of T. Théry, Fleury les Aubrais, France;

EMEC Essig Museum of Entomology, University of California, Berkeley, CA, USA;

QMOR Ouellet-Robert Entomological Collection, University of Montreal, QC, Canada;

UMSP University of Minnesota Insect Collection, St Paul, MN, USA;

USNM National Aphid Collection, National Museum of Natural History, Beltsville, MD, USA. 


\section{Taxon sampling}

All Essigella specimens published here were collected recently in the USA and Canada (TT and CF), or are found in the Sorensen Collection at EMEC. Specimens studied were mainly viviparous apterae. Some viviparous alatae also were studied in the case of $E$. patchae for which the holotype is an alate. Recently collected specimens were preserved in $95 \%$ ethanol after collecting and subsequently kept at $-20{ }^{\circ} \mathrm{C}$ or $-80{ }^{\circ} \mathrm{C}$. DNA extraction of at least one specimen per population was realized. It was non-destructive (Favret 2005), permitting us to keep the specimen as voucher. Those specimens were identified using the keys of Sorensen (1994) and Blackman and Eastop (2017). We compared our material with the type specimens of the valid species, $E$. californica (EMEC) and E. pini (UMSP), as well as those of their synonyms E. claremontiana Hottes, 1957, E. cocheta Hottes, 1957, E. monelli Hottes, 1957, E. pineti Hottes, 1957, E. swaini Hottes, 1957, for E. californica, and E. patchae for E. pini (EMEC, USNM). We also compared specimens of new taxa and of $E$. patchae with other E. californica specimens from the Sorensen Collection (EMEC), and of E. pini from UMSP and USNM.

\section{Preparation, measurements, and photographs}

All new material was slide-mounted in Canada balsam and deposited in QMOR, CTT, and USNM, in the case of holotypes. Preparations were thick to reduce deformation due to compression. As far as possible, appendages were placed so that they be strictly horizontal permitting correct length and width measurements as well as to ascertain the correct location of dorsal and ventral setae of the hind femora and tibiae. Body length was measured from the frontal margin of the head to the posterior margin of the $7^{\text {th }}$ abdominal segment. The abdominal tergum being sclerotized with most segments fused, the cauda and $8^{\text {th }}$ segment sometimes telescope into the $7^{\text {th }}$, making standardized measurements difficult across specimens. Because of the likely deformation of the body due to a variable number of embryos, width measurements were taken only of the head, between the frontal interior margins of the compound eyes. Lengths of appendages were measured at their longest, including condyles, widths were measured at the widest part of the appendages. The length of the processus terminalis was taken from the distal margin of primary rhinarium to the apex of the antenna. The following abbreviations are applied:

BL body length;

LAIII length of third antennal segment;

LAIV length of fourth antennal segment;

LAV length of fifth antennal segment;

LPRIV length of primary rhinarium on fourth antennal segment;

LPRV length of primary rhinarium on fifth antennal segment;

LPT length of processus terminalis;

HWE head width at eyes; 


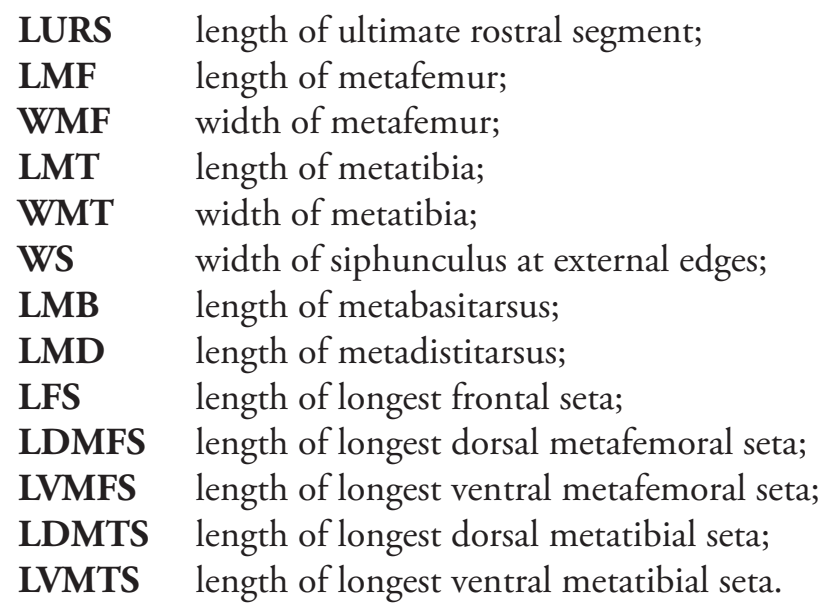

Entire non-prepared specimens were photographed with a Carl Zeiss Discovery. V20 stereoscope using an AxioCam HRc camera and a Zen 2012 Carl Zeiss Software, version 1.1.1.0. Pictures of slide-mounted specimens were realized using light microscope Nikon Eclipse E600 with differential interference contrast (DIC) and photographed by Nikon DS-Fi camera. Scanning electron microscope (SEM) photos were taken at the University of Silesia in Katowice (Poland) using a Hitachi SU8010 Field Emission Scanning Electron Microscope (FE-SEM) (Hitachi High-Technologies Corporation, Tokyo, Japan) at 5, 10 and $15 \mathrm{kV}$ accelerating voltage with a secondary electron detector (ESD). For specimen preparation for SEM pictures, we followed the protocol of Kanturski et al. (2015). Measurements in diagnoses and descriptions are given in microns $(\mu \mathrm{m})$ with standard deviation.

\section{Molecular data}

The three new species were primarily revealed in the study of Théry et al. (in press) using DNA sequences of the genomes of the mitochondrion (ATP6, COI) and the obligate bacterial endosymbiont Buchnera aphidicola $(G n d)$ within populations of $E$. californica sensu lato. Indeed, ATPG and Gnd show similar properties as COI in species discrimination in barcoding (Hebert et al. 2003a, b, Chen et al. 2013, Lee et al. 2014). Sequence lengths were 663 base pairs (bp), 658 bp and 749 bp for ATP6, COI and $G$ nd, respectively (see Théry et al. in press, for GenBank accession numbers and other details).

\section{Taxonomy}

The following species, including $E$. patchae, belong to the E. californica species complex, which also includes E. hoerneri Gillette \& Palmer, 1924 (Sorensen 1994) (see 
discussion). All of these species, as well as E. pini, exhibit six dorsal setae at their $3^{\text {rd }}$ and $4^{\text {th }}$ abdominal segments (Sorensen 1994). However, this character is homoplastic within Essigella as E. pini and the E. californica complex are not closely related (Théry et al. in press); it is used here to distinguish the species of the E. californica complex and $E$. pini from the other species of the genus. Morphological and ecological (host plant identity) comparisons of specimens of the new species with type material of synonym species of E californica and E. hoerneri permitted to reject the possibility that our new species correspond to one of those synonyms.

\section{Essigella domenechi sp. n.}

http://zoobank.org/390343A7-D620-4578-93A8-A5BBBF7FE00F

Figure 1d

Holotype. viviparous aptera, USA, California, Alpine Co., $38.328^{\circ} \mathrm{N} 119.637^{\circ} \mathrm{W}$, 10.vii.2013, on Pinus albicaulis, T. Théry \& C. Favret leg. (USNM). Paratypes. 8 viviparous apterae, same data as holotype (QMOR, CTT).

Diagnosis. Like species of the E. californica complex and E. pini, E. domenechi sp. n. has its $3^{\text {rd }}$ and $4^{\text {th }}$ abdominal dorsal terga usually bearing six setae. The species can be distinguished from $E$. patchae by the presence of rows of spinules on the URS (absent or faint in E. patchae; Fig. 2b, d); from E. pini by a relatively elongate URS with subparallel lateral margins (URS with margins rounded and convergent at base in E. pini; Fig. 2a, c); from E. gagnonae sp. n. and E. sorenseni sp. n. with the following characters: tibiae and femora more or less concolorous showing almost or same color as that of body (pro- and metatibiae and metafemora conspicuously darkened in E. sorenseni sp. n., pro- and metatibiae sometimes slightly darkened in E. gagnonae sp. n.), dorsal tegument thick; width of head between eyes $=300.7 \pm 14.2(289.0 \pm 13.3$ for E. gagnonae sp. n., and $353.6 \pm 15.3$ for E. sorenseni sp. n.); ratio of $3^{\text {rd }} / 5^{\text {th }}$ antennal segments $<$ 1.6 ( $<1.6$ for E. gagnonae sp. n. but > 1.6 in E. sorenseni sp. n.); overall pubescence short or medium-sized with average length of the longest dorsal seta of metafemora $=$ $29.7 \pm 4.2$ (59.8 \pm 9.8 for E. gagnonae sp. n., and $51.2 \pm 10.7$ for E. sorenseni sp. n.; average length of the longest ventral seta of metafemora $=32.6 \pm 4.5(43.1 \pm 5.4$ for E. gagnonae sp. n., and $54.4 \pm 5.6$ for E. sorenseni sp. n.); average length of the longest dorsal seta of metatibiae $=44.0 \pm 8.1(85.7 \pm 10.8$ for E. gagnonae sp. n., and $76.4 \pm$ 15.8 for E. sorenseni sp. n.); average length of the longest ventral seta of metatibiae = $37.5 \pm 7.0$ ( $49.4 \pm 9.5$ for E. gagnonae sp. n., and $67.7 \pm 12.0$ for E. sorenseni sp. n.); average length of the longest frontal seta $=32.6 \pm 7.5$ (58.7 \pm 8.3 for E. gagnonae sp. n., and $53.4 \pm 11.9$ for E. sorenseni sp. n.); average number of setae of the genital plate $=22.0 \pm 2.1(23.6 \pm 2.1$ for E. gagnonae sp. n., and $31.6 \pm 1.7$ for E. sorenseni sp. n.). Essigella domenechi sp. n. is morphologically not distinguishable from E. californica, the latter being highly variable, nor from E. hoerneri. Essigella domenechi sp. n. can be separated from E. californica, E. gagnonae sp. n., E. hoerneri and E. sorenseni sp. n. with the DNA characters shown in Table 1. 

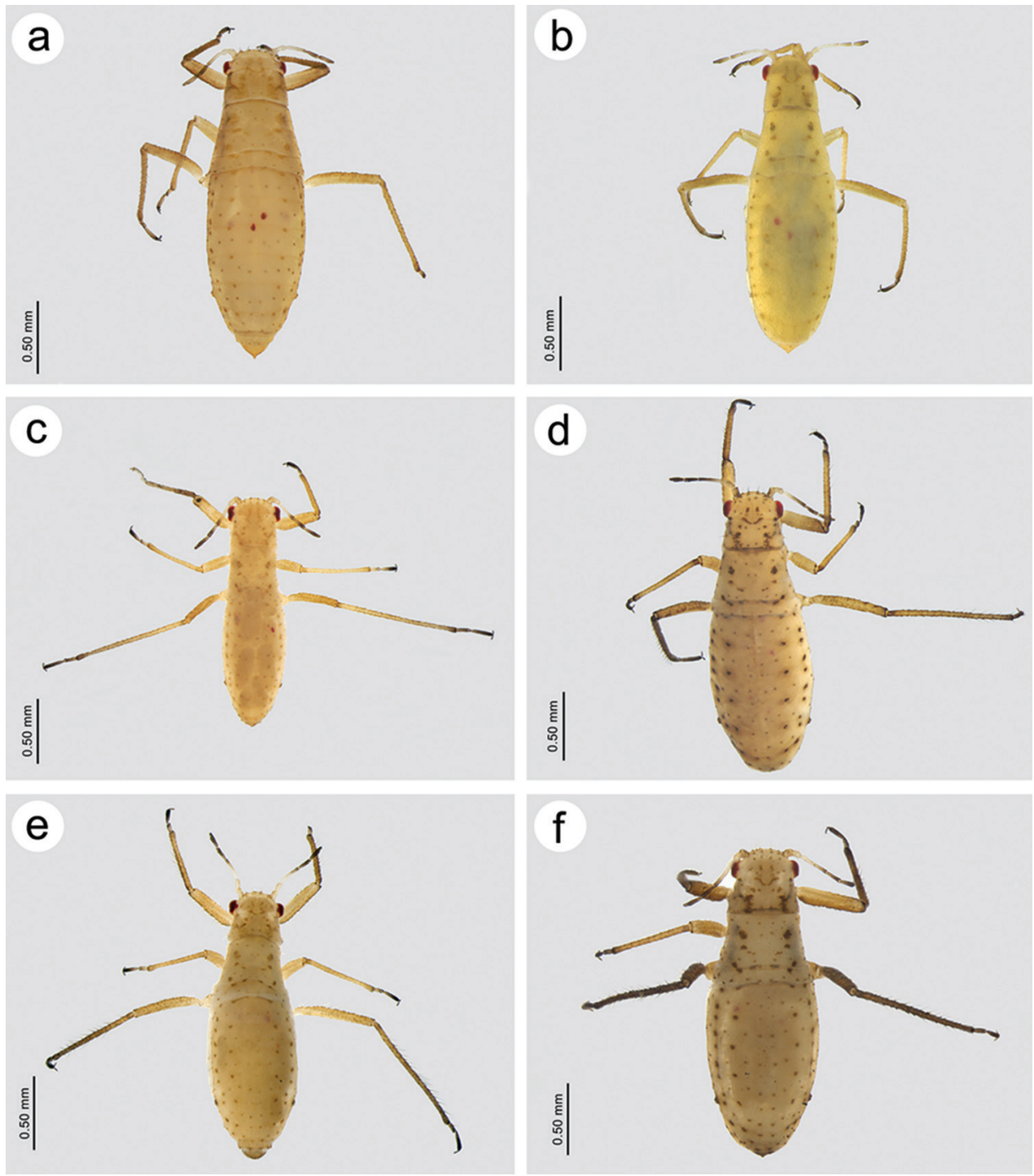

Figure I. Habitus of viviparous apterae of $\mathbf{a}$ Essigella pini $\mathbf{b}$ E. patchae $\mathbf{c}$ E. californica $\mathbf{d}$ E. domenechi sp. n. e E. gagnonae sp. n. f. E. sorenseni sp. n.

Description. Viviparous apterae (prepared specimens): body with pale tegument, with visible pigmented scleroites; dorsal tegument visibly thicker, sclerotized. Legs quite pale, concolorous, more or less the same color than that of body. Antennae pale, the $5^{\text {th }}$, the $4^{\text {th }}$ and the apical third part of the $3^{\text {rd }}$ segment of antennae darkened. URS elongated, with lateral margins subparallel, bearing rows of spinules. Overall pubescence short to medium-sized, dorsal setae of appendages incrassate, ventral ones acute. Terga of abdominal segments 3 and 4 with six dorsal setae. Genital plate with 19-25 setae $(22.0 \pm 2.1)(n=6)$. Cauda obvious but not too protruding, apically rounded, 

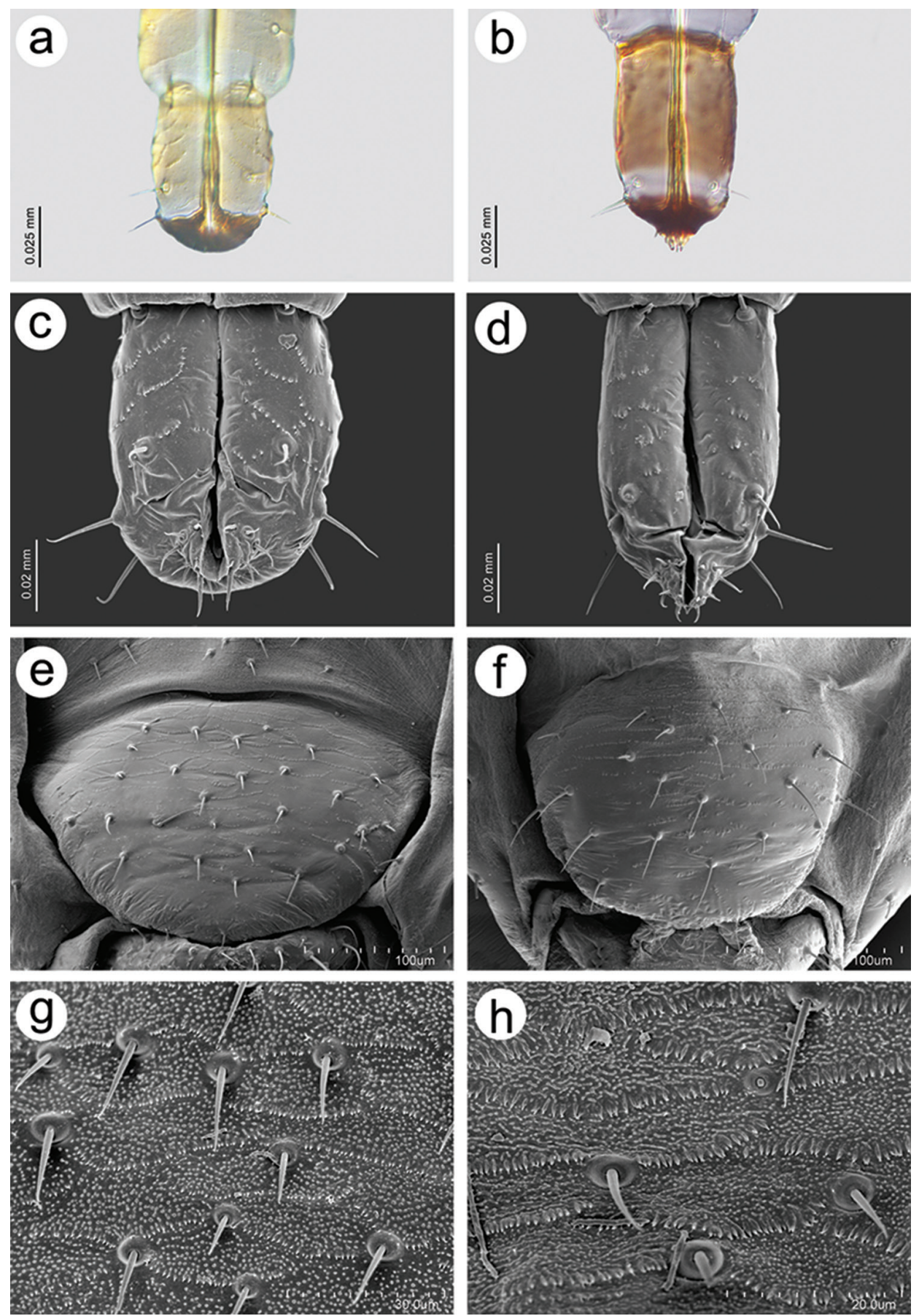

Figure 2. Morphological structures in Essigella pini and in E. patchae: a URS in E. pini (slide-mounted specimen) b URS in E. patchae (slide-mounted specimen) c URS in E. pini (SEM) d URS in E. patchae (SEM) e genital plate in $E$. pini (SEM) $\mathbf{f}$ genital plate in $E$. patchae (SEM) $\mathbf{g}$ details in genital plate in $E$. pini (SEM) $\mathbf{h}$ details in genital plate in E. patchae (SEM). 
Table I. Diagnostic nucleotide differences between $E$. domenechi sp. n. and E. californica, E. gagnonae sp. n., E. hoerneri, and E. sorenseni sp. n. for ATP6, COI, and Gnd.

\begin{tabular}{|c|c|c|c|c|c|c|c|c|c|c|c|c|c|c|}
\hline \multirow{2}{*}{$\begin{array}{c}\text { Gene } \\
\text { Site }\end{array}$} & \multicolumn{4}{|c|}{$\operatorname{ATP6}(663$ bp) } & \multicolumn{8}{|c|}{$C O I(658 \mathrm{bp})$} & \multicolumn{2}{|c|}{ Gnd (749 bp) } \\
\hline & 4 & 71 & 227 & 324 & 190 & 229 & 334 & 386 & 418 & 565 & 619 & 625 & 219 & 621 \\
\hline E. domenechi sp. n. & $\mathrm{C}$ & $\mathrm{C}$ & $\mathrm{C}$ & G & G & G & A & G & C & G & G & G & C & $\mathrm{C}$ \\
\hline E. gagnonae sp. n. & $\mathrm{T}$ & $\mathrm{T}$ & $\mathrm{T}$ & A & A & A & $\mathrm{T}$ & A & $\mathrm{T}$ & A & A & A & A & A \\
\hline E. sorenseni sp. n. & $\mathrm{T}$ & $\mathrm{T}$ & $\mathrm{T}$ & A & A & A & $\mathrm{T}$ & $\mathrm{A}$ & $\mathrm{T}$ & A & A & A & A & A \\
\hline E. californica & $\mathrm{T}$ & $\mathrm{T}$ & $\mathrm{T}$ & A & A & A & $\mathrm{T}$ & A & $\mathrm{T}$ & A & A & A & A & A \\
\hline E. hoerneri & $\mathrm{T}$ & $\mathrm{T}$ & $\mathrm{T}$ & A & A & $\mathrm{A}$ & $\mathrm{T}$ & A & $\mathrm{T}$ & A & A & A & A & A \\
\hline
\end{tabular}

slightly turned upward. BL: 1600-2100 (1800 \pm 170$)(\mathrm{n}=7)$. HWE: 283.2-326.0 $(300.7 \pm 14.2)(\mathrm{n}=7)$, LAIII: $162.2-184.6(171.8 \pm 6.5)(\mathrm{n}=13)$, LAIV: $96.4-106.7$ $(101.0 \pm 4.1)(n=9)$, LAV: $113.7-124.4(120.2 \pm 4.1)(n=5)$, LPRIV: $20.8-25.8$ $(23.0 \pm 1.6)(\mathrm{n}=9)$, LPRV: $17.6-21.9(19.6 \pm 1.4)(\mathrm{n}=9)$, LPT: $8.5-14.5(11.9 \pm 1.9)$ $(\mathrm{n}=9)$, LURS: $71.4-79.2(75.2 \pm 2.8)(\mathrm{n}=6)$, LMF: 675.7-728.8 $(708.3 \pm 24.2)(\mathrm{n}=$ 6), WMF: $68.2-77.3(74.9 \pm 2.9)(\mathrm{n}=11)$, LMT: $975.1-1074.4(1027.8 \pm 38.2)(\mathrm{n}=$ 9), WMT: 36.8-43.9 (41.4 \pm 2.2$)(\mathrm{n}=12)$, WS: 36.7-43.5 $(40.4 \pm 2.2)(\mathrm{n}=9)$, LMB: 107.2-114.4 (110.9 \pm 2.3$)(\mathrm{n}=11)$, LMD: 189.4-206.4 (194.9 \pm 6.9$)(\mathrm{n}=11), \mathrm{LFS}:$ 18.7-39.5 (32.6 \pm 7.5$)(\mathrm{n}=7)$, LDMFS: $25.2-36.8(29.7 \pm 4.2)(\mathrm{n}=12)$, LVMFS: 26.1-44.0 (32.6 \pm 4.5$)(\mathrm{n}=12)$, LDMTS: 33.7-61.8 $(44.0 \pm 8.1)(\mathrm{n}=12)$, LVMTS: $24.7-48.1(37.5 \pm 7.0)(\mathrm{n}=12)$.

Comments. USA, California, on Pinus albicaulis Engelmann, known from Stanislaus National Forest at high elevation (type series). The species probably occurs in other high mountains where $P$. albicaulis is present. This species corresponds to the $E$. californica population living on P. albicaulis (cluster H3) shown in Théry et al. (in press).

Etymology. This species is dedicated to Boris Domenech, PhD student at the University of Montreal (QC, Canada) for his comments in genetic analyses with which the species was discovered.

\section{Essigella gagnonae sp. $\mathbf{n}$.}

http://zoobank.org/53A36CBB-AE8E-42FD-B792-C431EE48BBD4

Figs 1e, $3 \mathrm{~b}$

Holotype. viviparous aptera, USA, Nevada, Douglas Co., $38.999^{\circ} \mathrm{N} 119.896^{\circ} \mathrm{W}$, 10.vii.2013, on Pinus monticola, T. Théry \& C. Favret leg. (USNM). Paratypes. 1 viviparous aptera, same data as holotype (QMOR); 12 viviparous apterae, California, El Dorado Co., $38.834^{\circ} \mathrm{N} 120.042^{\circ} \mathrm{W}, 09 . v i i .2013$, on Pinus monticola, T. Théry \& C. Favret leg., specimens on 10 slides (QMOR, CTT); 5 viviparous apterae, California, Lassen Co., HWY 89, 6 km N Jct HWY 36 \& 89, 6600', S of Lassen Nat'l Park (77G20), 10.vii.1977, on Pinus monticola, J. T. Sorensen leg., specimens on 1 slide (EMEC); 5 viviparous apterae, Californica, Alpine Co., E side Ebbett's Pass, HWY 4, 3 km E summit (77G41), 17.vii.1977, on Pinus monticola, J. T. Sorensen leg., speci- 
mens on 1 slide (EMEC); 13 viviparous apterae, Washington, Kitsap Co., 8 km S Hood Canal Bridge, HWY 3 (78G49), 09.vii.1978, on Pinus monticola, J. T. Sorensen leg., specimens on 3 slides $(4+4+5)$ (EMEC); 8 viviparous apterae, Washington, Grays Harbor Co., 16 km W Amanda Park, HWY 101 (78G54), 10.vii.1978, on Pinus monticola, J. T. Sorensen leg., specimens on 2 slides $(4+4)($ EMEC); 5 viviparous apterae, Nevada, Washoe Co., Mt Rose, Summit, Cmpgd, Toiyabe Nat'l Forest (78H9), 02.viii.1978, on Pinus monticola, J. T. Sorensen leg., specimens on 2 slides (2 + 3) (EMEC).

Diagnosis. Like species of the E. californica complex and E. pini, E. gagnonae sp. n. has its $3^{\text {rd }}$ and $4^{\text {th }}$ abdominal dorsal terga usually bearing six setae. It can be distinguished from $E$. patchae by the presence of spinules on the URS (absent or faint in $E$. patchae; Fig. 2b, d); from $E$. pini by a relatively elongate URS with subparallel lateral margins (URS with margins rounded and convergent at base in E. pini; Fig 2a, c); from E. domenechi sp. n. and E. sorenseni sp. n. with the following characters: legs ranging from concolorous and slightly darker than body, to pro- and metatibiae slightly darkened with mesotibiae lighter and metafemora pale (tibiae concolorous in E. domenechi sp. n., pro- and metatibiae, and metafemora conspicuously darkened in E. sorenseni sp. n.); width of head between eyes $=289.0 \pm 13.3(300.7 \pm 14.2$ for $E$. domenechi sp. n., and $353.6 \pm 15.3$ for E. sorenseni sp. n.); ratio of $3^{\text {rd }} / 5^{\text {th }}$ antennal segments $<$ 1.6 ( $<1.6$ for E. domenechi sp. n. but $>1.6$ in E. sorenseni sp. n.); overall pubescence medium-sized to long with average length of the longest dorsal setae of metafemora $=$ $59.8 \pm 9.8$ (29.7 \pm 4.2 for E. domenechi sp. n., and $51.2 \pm 10.7$ for E. sorenseni sp. n.); average length of the longest ventral seta of metafemora $=43.1 \pm 5.4$ (32.6 \pm 4.5 for $E$. domenechi sp. n., and $54.4 \pm 5.6$ for E. sorenseni sp. n.); average length of the longest dorsal seta of metatibiae $=85.7 \pm 10.8(44.0 \pm 8.1$ for $E$. domenechi sp. n., and 76.4 \pm 15.8 for E. sorenseni sp. n.); average length of the longest ventral seta of metatibiae $=49.4 \pm 9.5(37.5 \pm 7.0$ for E. domenechi sp. n., and $67.7 \pm 12.0$ for E. sorenseni sp. n.); average length of the longest frontal seta $=58.7 \pm 8.3(32.6 \pm 7.5$ for $E$. domenechi sp. n., and $53.4 \pm 11.9$ for E. sorenseni sp. n.); average number of setae of the genital plate $=23.6 \pm 2.1(22.0 \pm 2.1$ for $E$. domenechi sp. n., and $31.6 \pm 1.7$ for E. sorenseni sp. n.). Essigella gagnonae sp. n. is for now morphologically not distinguishable from $E$. californica, the latter being highly variable, nor from E. hoerneri. Essigella gagnonae sp. n. can be separated from E. californica, E. domenechi sp. n., E. hoerneri, and E. sorenseni sp. n. with the DNA characters shown in Table 2.

Description. Viviparous apterae (prepared specimens): body with pale tegument sometimes slightly yellowish, with visible pigmented scleroites. Legs ranging from concolorous, slightly darker than body, to pro- and metatibiae slightly darkened, darker than body and mesotibiae. Antennae pale, the $5^{\text {th }}$, the $4^{\text {th }}$ and the apical third part of the $3^{\text {rd }}$ segment darkened. URS elongated, with lateral margins subparallel, bearing rows of spinules. Overall pubescence medium-sized to long, dorsal setae of appendages incrassate, ventral ones acute, in specimens with very long dorsal setae in metafemora and metatibiae (> $100 \mu \mathrm{m})$, these setae almost acute to acute (Fig. 3b), straight to sinuated. Terga of abdominal segments 3 and 4 with six dorsal setae. Genital 
Table 2. Diagnostic nucleotide differences between E. gagnonae sp. n. and E. californica, E. domenechi sp. n., E. hoerneri and E. sorenseni sp. n. for ATPG, COI, and Gnd.

\begin{tabular}{l|c|c|c|c|c}
\hline \multicolumn{1}{c|}{ Gene } & ATP6 (663 bp) & \multicolumn{3}{|c|}{ COI (658 bp) } & Gnd (749 bp) \\
\hline \multicolumn{1}{c|}{ Site } & $\mathbf{2 6 0}$ & $\mathbf{2 8}$ & $\mathbf{2 3 5}$ & $\mathbf{2 7 1}$ & $\mathbf{6 6 5}$ \\
\hline E. gagnonae sp. n. & G & G & C & C & C \\
\hline E. domenechi sp. n. & A & A & T & A & T \\
\hline E. sorenseni sp. $\mathrm{n}$. & A & A & T & A & A \\
\hline E. californica & A & A & T & A & A \\
\hline E. hoerneri & A & A & T & A & T \\
\hline
\end{tabular}

plate with $21-26$ setae $(23.6 \pm 2.1)(\mathrm{n}=9)$. Cauda obvious but not too protruding, apically rounded, slightly turned upward. BL: 1600-2000 (1800 \pm 130$)(\mathrm{n}=19)$. HWE: $271.0-311.9(289.0 \pm 13.3)(\mathrm{n}=13)$, LAIII: $157.6-197.4(178.1 \pm 11.1)(\mathrm{n}$ = 29), LAIV: $90.2-111.6(99.7 \pm 6.3)(\mathrm{n}=33), \mathrm{LAV}: 116.0-141.6(125.4 \pm 5.8)(\mathrm{n}$ = 20), LPRIV: $21.5-29.1(24.3 \pm 1.8)(\mathrm{n}=21)$, LPRV: $18.5-22.6(20.6 \pm 1.2)(\mathrm{n}=$ 18), LPT: $7.6-16.8(12.1 \pm 2.5)(\mathrm{n}=23)$, LURS: 64.5-79.8 $(72.0 \pm 3.8)(\mathrm{n}=18)$, LMF: 650.3-798.5 (707.3 \pm 38.6) $(\mathrm{n}=22)$, WMF: 69.5-104.6 (87.0 \pm 10.8$)(\mathrm{n}=$ 29), LMT: 876.1-1104.2 (999,9 \pm 67.4$)(\mathrm{n}=25)$, WMT: 33.8-52.5 $(42.3 \pm 4.1)(\mathrm{n}=$ 40), WS: 34.4-42.6 (38,9 \pm 2.5$)(\mathrm{n}=18), \mathrm{LMB}: 101.8-131.0(116.1 \pm 8.0)(\mathrm{n}=36)$, LMD: $180.3-209.9(195.0 \pm 8.6)(\mathrm{n}=34), \mathrm{LFS}: 44.4-80.2(58.7 \pm 8.3)(\mathrm{n}=26), \mathrm{LD}-$ MFS: 42.0-82.9 (59.8 \pm 9.8$)(\mathrm{n}=43)$, LVMFS: $31.5-52.6(43.1 \pm 5.4)(\mathrm{n}=42), \mathrm{LD}-$ MTS: 60.9- $107.7(85.7 \pm 10.8)(\mathrm{n}=46)$, LVMTS: $30.5-74.5(49.4 \pm 9.5)(\mathrm{n}=46)$.

Comments. USA, California, Nevada, and Washington, on Pinus monticola Douglas ex D. Don. The species occurs in elevated places where $P$. monticola is present. This species corresponds to the E. californica population living on P. monticola (cluster $\mathrm{H} 2$ ) shown in Théry et al. (in press).

Etymology. This species is dedicated to Édeline Gagnon, PhD student at the University of Montreal (QC, Canada) for her help in genetic analyses with which the species was discovered.

\section{Essigella sorenseni sp. $\mathbf{n}$.}

http://zoobank.org/4C35698B-A28C-4794-8AE8-C9A6BA84541F

Figs 1f, 3a

Holotype. viviparous aptera, USA, California, Sonoma Co., $38.534^{\circ} \mathrm{N} 123.276^{\circ} \mathrm{W}$, 02.vii.2013, on Pinus muricata, T. Théry \& C. Favret leg. (QMOR). Paratypes. 14 viviparous apterae, same data than holotype, specimens on 14 slides (QMOR, CTT); 3 viviparous apterae, California, Mendocino Co., $38.984^{\circ} \mathrm{N} 123.696^{\circ} \mathrm{W}, 03 . v i i .2013$, on Pinus muricata, T. Théry \& C. Favret leg., specimens on 3 slides (QMOR, CTT); 6 viviparous apterae, California, Mendocino Co., HWY 1, $5 \mathrm{~km}$ of Albion, Little River Road, 23.vii.1977, on Pinus muricata, 77G52, J. T. Sorensen leg., specimens on 3 

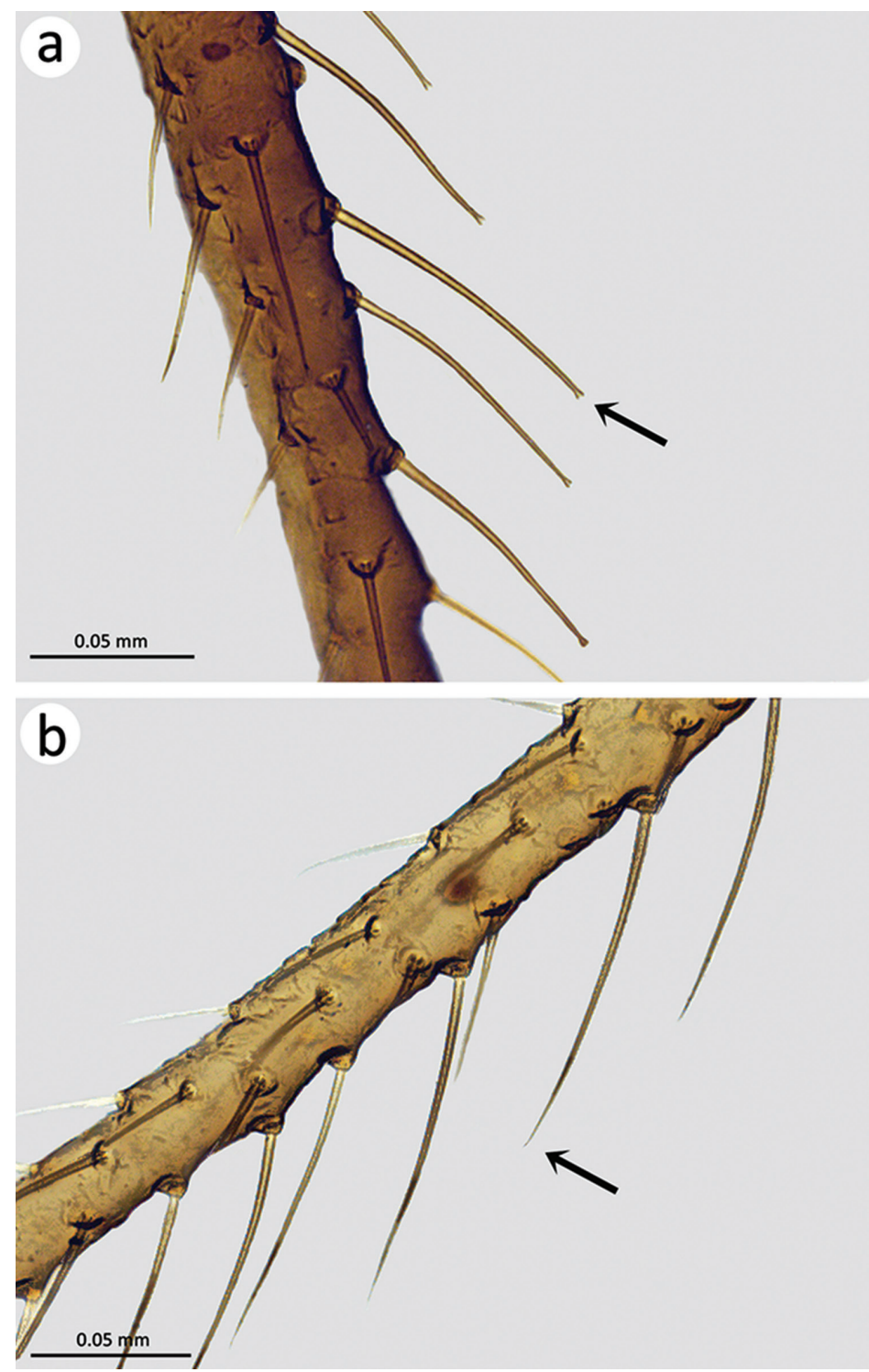

Figure 3. Details of dorsal setae of metatibia in a E. sorenseni sp. n. (slide-mounted specimen) b E. gagnonae sp. n. (slide-mounted specimen).

slides $(2+2+2)$ EMEC); 13 viviparous apterae, California, Humbodlt Co., nr Little River State Beach, 17 km N Arcata, HWY 101, 04.vii.1978, on Pinus muricata, 78G3, J. T. Sorensen leg., specimens on 4 slides $(4+4+4+1)$ (EMEC).

Diagnosis. Like species of the E. californica complex and E. pini, E. sorenseni sp. $\mathrm{n}$. has its $3^{\text {rd }}$ and $4^{\text {th }}$ abdominal dorsal terga usually bearing six setae. It can be distinguished from $E$. patchae by the presence of spinules on the URS (absent or faint in $E$. patchae; Fig 2 b, d); from $E$. pini by a relatively elongate URS with subparallel 
lateral margins (URS with margins rounded and convergent at base in E. pini; Fig 2a, c); from E. domenechi sp. n. and E. gagnonae sp. n. with the following characters: usually pro- and metatibiae conspicuously darkened with mesotibiae always lighter, metafemora darkened (tibiae concolorous, metafemora pale in E. domenechi sp. n., concolorous or with pro- and metatibiae slightly darkened with mesotibiae lighter, metafemora pale in E. gagnonae sp. n.); width of head between eyes = 353.6 \pm 15.3 (300.7 \pm 14.2 for $E$. domenechi sp. n., and $289.0 \pm 13.3$ for E. gagnonae sp. n.); ratio of $3^{\text {rd }} / 5^{\text {th }}$ antennal segments $>1.6(<1.6$ for E. domenechi sp. n. and E. gagnonae sp. n.); overall pubescence medium-sized to long with average length of the longest dorsal setae of metafemora $=51.2 \pm 10.7(29.7 \pm 4.2$ for $E$. domenechi sp. n., and 59.8 \pm 9.8 for E. gagnonae sp. n.); average length of the longest ventral seta of metafemora $=54.4 \pm 5.6$ (32.6 \pm 4.5 for E. domenechi sp. n., and for $43.1 \pm 5.4$ for E. gagnonae sp. n.); average length of the longest dorsal seta of metatibiae $=76.4 \pm 15.8(44.0 \pm$ 8.1 for E. domenechi sp. n., and $85.7 \pm 10.8$ for E. gagnonae sp. n.); average length of the longest ventral seta of metatibiae $=67.7 \pm 12.0$ (37.5 \pm 7.0 for $E$. domenechi sp. n., and $49.4 \pm 9.5$ for $E$. gagnonae sp. n.); average length of the longest frontal setae $=53.4 \pm 11.9$ (32.6 \pm 7.5 for $E$. domenechi sp. n., and for $58.7 \pm 8.3$ E. gagnonae sp. n.); average number of setae of the genital plate $=31.6 \pm 1.7(22.0 \pm 2.1$ for $E$. domenechi sp. n., and $23.6 \pm 2.1$ for E. gagnonae sp. n.). Essigella sorenseni sp. n. is for now morphologically not distinguishable from E. californica, the latter being highly variable, nor from E. hoerneri. E. sorenseni sp. n. can be separated from E. californica, E. domenechi sp. n., E. gagnonae sp. n., and E. hoerneri with the DNA characters shown in Table 3.

Description. Viviparous apterae (prepared specimens): body with a yellowish tegument more or less darkened at joints depending on the specimens, with conspicuous and pigmented scleroites. Legs usually with pro- and metatibiae conspicuously darkened, much darker than body and mesotibiae. Antennae pale, the $5^{\text {th }}$, the $4^{\text {th }}$ and the apical third part of the $3^{\text {rd }}$ segment darkened. URS elongated, with lateral margins subparallel, bearing rows of spinules. Overall pubescence medium-sized to long, dorsal setae of appendages incrassate, ventral ones acute, in specimens with very long dorsal setae on metafemora and metatibiae $(>100 \mu \mathrm{m})$, these setae not acute or seemingly acute but still incrassate (Fig 3a), the setae sometimes curved at base. Terga of abdominal segments 3 and 4 with six dorsal setae. Genital plate with 29-34 setae $(31.6 \pm 1.7)$ $(\mathrm{n}=10)$. Cauda obvious but not protruding, apically rounded, slightly turned upward. BL: 1900-2300 (2200 \pm 110$)(\mathrm{n}=21)$. HWE: 322.3-376.1 $(353,6 \pm 15.3)(\mathrm{n}=17)$, LAIII: $207.5-256.3(233.6 \pm 12.8)(\mathrm{n}=25)$, LAIV: $98.3-130.0(112.2 \pm 7.1)(\mathrm{n}=$ 34), LAV: $120.1-139.8(127.9 \pm 4.7)(\mathrm{n}=23)$, LPRIV: $19.9-27.8(24.1 \pm 1.8)(\mathrm{n}=$ 28), LPRV: $17.4-23.4(19.5 \pm 1.5)(\mathrm{n}=21), \mathrm{LPT}: 11.6-15.7(13.8 \pm 1.4)(\mathrm{n}=21)$, LURS: 74.1-86.4 $(80.5 \pm 3.2)(\mathrm{n}=21)$, LMF: 702.3-927.8 $(810.8 \pm 58.9)(\mathrm{n}=26)$, WMF: $87.5-128.9(103.1 \pm 11.3)(\mathrm{n}=36)$, LMT: $1064.2-1450.4(1233.4 \pm 95.1)$ $(\mathrm{n}=26)$, WMT: 49.5-76.0 (55.1 \pm 5.1$)(\mathrm{n}=37)$, WS: 39.0-44.6 $(41.4 \pm 1.7)(\mathrm{n}=$ 22), LMB: $118.5-140.3(130.3 \pm 6.4)(\mathrm{n}=38), \mathrm{LMD}: 183.4-212.5(198.1 \pm 7.9)(\mathrm{n}$ 
Table 3. Diagnostic nucleotide differences between E. sorenseni sp. n. and E. californica, E. domenechi sp. n., E. gagnonae sp. n., and E. hoerneri for ATP6, COI, and Gnd.

\begin{tabular}{l|c|c|c|c|c|c}
\hline \multicolumn{1}{c|}{ Gene } & \multicolumn{2}{c|}{ ATP6 (663 bp) } & COI $\mathbf{6 5 8} \mathbf{b p})$ & \multicolumn{3}{c}{ Gnd $\mathbf{( 7 4 9} \mathbf{b p})$} \\
\hline \multicolumn{1}{c}{ Site } & $\mathbf{1 1 0}$ & $\mathbf{3 9 9}$ & $\mathbf{2 4 7}$ & $\mathbf{1 9 8}$ & $\mathbf{4 0 7}$ & $\mathbf{4 3 1}$ \\
\hline E. sorenseni sp. n. & $\mathrm{C}$ & $\mathrm{C}$ & $\mathbf{T}$ & $\mathrm{T}$ & $\mathbf{C}$ & $\mathbf{G}$ \\
\hline E. domenechi sp. n. & $\mathrm{T}$ & $\mathrm{T}$ & $\mathrm{C}$ & $\mathrm{C}$ & $\mathrm{T}$ & $\mathrm{T}$ \\
\hline E. gagnonae sp. n. & $\mathrm{T}$ & $\mathrm{T}$ & $\mathrm{C}$ & $\mathrm{C}$ & $\mathrm{T}$ & $\mathrm{T}$ \\
\hline E. californica & $\mathrm{T}$ & $\mathrm{T}$ & $\mathrm{C}$ & $\mathrm{C}$ & $\mathrm{T}$ & $\mathrm{T}$ \\
\hline E. hoerneri & $\mathrm{T}$ & $\mathrm{T}$ & $\mathrm{C}$ & $\mathrm{C}$ & $\mathrm{T}$ & $\mathrm{T}$ \\
\hline
\end{tabular}

= 34), LFS: 31.9-82.7 (53.4 \pm 11.9$)(\mathrm{n}=25)$, LDMFS: $34.2-79.4(51.2 \pm 10.7)(\mathrm{n}=$ 45), LVMFS: 43.4-66.0 (54.4 \pm 5.6$)(\mathrm{n}=44)$, LDMTS: 47.7-113.8 $(76.4 \pm 15.8)(\mathrm{n}$ = 46), LVMTS: 45.9-92.2 (67.7 \pm 12.0$)(\mathrm{n}=45)$.

Comments. USA, California, on Pinus muricata D. Don, known from Humboldt, Mendocino, and Sonoma counties (type series), but probably present everywhere on the coastal range in California where P. muricata occurs. This species corresponds to the E. californica population living on $P$. muricata (cluster H1) shown in Théry et al. (in press).

Etymology. This species is dedicated to John T. Sorensen, aphid specialist who eminently revised the genus Essigella in 1994, for his advice and hospitality accorded to the authors (TT and CF) in California.

\section{Essigella patchae Hottes, 1957, stat. n.}

Figs $1 \mathrm{~b}, 2 \mathrm{~b}, \mathrm{~d}, \mathrm{f}, \mathrm{h}$

Essigella patchae Hottes, 1957: 98 (Type locality: "Stillwater, Maine"). Holotype viviparous alate in USNM. Sorensen 1994: 49 [synonymy with E. pini Wilson]. Status re-established.

Other examined material. 1 viviparous alate and 1 viviparous aptera, Canada, Québec, Saint-Hippolyte, N45.991 - W74.009, ix.2015, on Pinus strobus, C. Favret leg. (QMOR); 1 viviparous aptera, Saint-Hippolyte, N45.989 - W74.005, ix.2016, on Pinus strobus, T. Théry leg. (QMOR); 1 viviparous aptera, Saint-Hippolyte, N45.989 - W74.005, ix.2017, on Pinus strobus, T. Théry leg. (QMOR).

Diagnosis. Like species of the E. californica complex and E. pini, E. patchae has its $3^{\text {rd }}$ and $4^{\text {th }}$ dorsal abdominal terga usually with six setae. Essigella patchae can be distinguished from the other species of the E. californica complex species and from $E$. pini by its ultimate rostral segment (URS) exhibiting no or barely visible rows of spinules (Fig. 2b, d), which are clearly visible in other species of the E. californica complex and also in E. pini (Fig. 2a, c). Essigella patchae can also be differentiated from E. pini by having the general shape of the URS more elongated with lateral margins almost 
parallel (Fig. 2b, d) (margins more rounded and convergent at base in E. pini; Fig. $2 \mathrm{a}, \mathrm{c})$; shorter cauda than that of $E$. pini which can be elongated and acute; genital plate with fewer setae (15-20 vs 26-30 in E. pini), longer in E. patchae in comparison with $E$. pini (Fig. 2e, f), with spinules of the genital plate tegument more developed in E. patchae (Fig. 2g, h).

Host plant and distribution. The species is currently known from its type locality in Maine (USA) and from one locality in Quebec (Canada) on Pinus strobus Linnaeus (see discussion).

\section{Simplified key to species of the Essigella californica complex, for viviparous apterae}

Due to the variability of preparation, notably cover slip-induced deformations, teneral specimens, and general morphological variability, several specimens and the identity of the host plant are required to best use this key.

1 Dorsal terga 3 and 4 usually with six setae.

E. californica complex, E. pini...2

- $\quad$ Dorsal terga 3 and 4 usually with more than six setae

$2 \quad$ Western North American species ......................................................... 3

- $\quad$ Eastern North American species...............................................................7 7

3 On pinyon pines (Pinus cembroides, P. edulis, P. monophylla, P. quadrifolia) ... E. boerneri

Ratio of LAIII / LAV > 1.6 (1.66-1.94), number of setae on genital plate > 27 (29-34), on P. muricata E. sorenseni sp. n. Ratio of LAIII / LAV < 1.6 (1.29-1.54), number of setae on genital plate < 27 (19-26)

Dorsal setae of metafemora $(25.2-36.8 \mu \mathrm{m})$ and of metatibiae (33.7-61.8 $\mu \mathrm{m})$ short, on P. albicaulis .E. domenechi sp. n.

Dorsal setae of metafemora $(42.0-82.9 \mu \mathrm{m})$ and of metatibiae (60.9-107.7 $\mu \mathrm{m})$ long, on P. monticola.

E. gagnonae sp. n.

Ultimate Rostral Segment (URS) with rows of spinules; sides of URS convex, convergent at base (Fig $2 \mathrm{a}, \mathrm{c}$ ), number of setae on genital plate $>24$ (26-30)

- $\quad$ Ultimate Rostral Segment (URS) without or with barely visible rows of spinules (Fig 2b, d); sides of URS subparallel, not convergent at base, number of setae on genital plate $<24(15-20)$ 


\section{Catalogue of Essigella species}

Genus Essigella del Guercio, 1909: 329

Type species : Lachnus californicus Essig, 1909: 1

= Archeoessigella Sorensen, 1994: 21; [new synonym]

= Lambersella Sorensen, 1994: 29; [new synonym]

Essigella alyeska Sorensen, 1988: 118; Sorensen 1994: 72

Essigella californica (Essig), 1909: 1; Sorensen 1994: 53

= Lachnus californicus Essig, 1909: 1

= Essigella claremontiana Hottes, 1957: 79 [synonymy by Sorensen 1994: 53]

= Essigella cocheta Hottes, 1957: 82 [synonymy by Sorensen 1994: 53]

= Essigella monelli Hottes, 1957: 95 [synonymy by Sorensen 1994: 53]

= Essigella pineti Hottes, 1957: 101 [synonymy by Sorensen 1994: 53]

= Essigella swaini Hottes, 1957: 105 [synonymy by Sorensen 1994: 53]

Essigella critchfieldi Sorensen, 1994: 75

Essigella domenechi sp. n.

Essigella eastopi Sorensen, 1994: 30

Essigella essigi Hottes, 1957: 84; Sorensen 1994: 45

Essigella fusca fusca Gillette \& Palmer, 1924: 6 ; Sorensen 1994: 34

= Essigella fusca Gillette \& Palmer, 1924: 6

= Essigella agilis Hottes, 1957: 71 [synonymy by Sorensen 1994: 34]

= Essigella palmerae Hottes, 1957: 96 [synonymy by Sorensen 1994: 34]

Essigella fusca voegtlini Sorensen, 1994: 39

Essigella gagnonae sp. $\mathrm{n}$.

Essigella hillerislambersi Sorensen, 1994: 41

Essigella hoerneri Gillette \& Palmer, 1924: 5; Sorensen 1994: 62

= Essigella gillettei Hottes, 1957: 88 [synonymy by Sorensen 1994: 62]

= Essigella maculata Hottes, 1957: 93 [synonymy by Sorensen 1994: 62]

Essigella kathleenae Sorensen, 1988: 115; Sorensen 1994: 26

Essigella kirki Sorensen, 1988: 121; Sorensen 1994: 22

Essigella knowltoni braggi Hottes, 1957: 73; Sorensen 1994: 84

= Essigella braggi Hottes, 1957: 73 [new status by Sorensen 1994: 84]

= Essigella robusta Hottes, 1957: 103 [synonymy by Sorensen 1994: 84]

Essigella knowltoni knowltoni Hottes, 1957: 92 [new status by Sorensen 1994: 78]

= Essigella knowltoni Hottes, 1957: 92

Essigella patchae Hottes, 1957: 98; Sorensen 1994: 49; [stat. n.]

Essigella pini Wilson, 1919: 2; Sorensen 1994: 49

Essigella sorenseni $\mathrm{sp} . \mathrm{n}$.

Essigella wilsoni Hottes, 1957: 106; Sorensen 1994: 67

= Essigella pergandei Hottes, 1957: 100 [synonymy by Sorensen 1994: 67]

= Essigella oregonensis Hottes, 1958: 155 [synonymy by Sorensen 1994: 67] 


\section{Discussion}

\section{Essigella californica}

Sorensen, in his revision of the genus Essigella (1994) had already documented the existence of different host-associated groups within E. californica. He notably mentioned populations living on Pinus flexilis E. James and P. lambertiana Douglas, populations that he nevertheless considered as exhibiting intraspecific variation (Sorensen 1983, 1994). Populations from those two pine species were not considered in the study of Théry et al. (in press) and it is possible that they correspond to yet two more cryptic species. Essigella californica is known to live on at least 34 Pinus species (Kimber et al. 2013) and it is likely that other cryptic species await discovery. We are unable to fully evaluate the species complex here due to a lack of material. The taxonomic nature of Essigella californica continues to be a complex issue meriting further study. Such a study would require substantial material of representative populations from as many known host plants as possible. A redescription of this species and the members of its complex would require morphometric data and multivariate analyses as per Sorensen (1994), combined with molecular phylogenetic and species delimitation methods as per Théry et al. (in press).

\section{Essigella patchae and E. pini}

Essigella pini is known to be oligophagous on Pinus and according to Sorensen (1994), it can be found on pine species of the subgenus Pinus, section Trifoliae, subsection Contortae (notably on P. virginiana Miller), subsection Australes (notably on P. taeda Linnaeus), and on pine species of the subgenus Strobus, section Quinquefoliae, subsection Strobus (notably on P. strobus). It may be also found on species of subsection Sylvestres (Sorensen 1994). The type specimen of E. pini was collected in Maryland on P. virginiana (Wilson 1919; Sorensen 1994) whereas that of E. patchae was collected in Maine on P. strobus (Hottes 1957; Sorensen 1994). Genetic material analysed by Théry et al. (in press) came from a Canadian specimen of E. patchae collected on $P$. strobus and a US specimen of E. pini collected on P. rigida (subsection Australes). Our first suspicions are that $E$. patchae could be a more northern species that would feed on pines of subsection Strobus whereas E. pini would be more southern developing on pines of both subsections Australes and Contortae. It could appear curious that Sorensen did not discriminate both species, even though they are morphologically very close. Actually, Sorensen himself collected only species occurring in the western part of USA. Because E. pini and E. patchae are the only species occurring in the East, all E. pini and E. patchae specimens that Sorensen studied came from other collections and represented a smaller specimen sample in comparison with other species. Considering the list of specimens Sorensen (1994) studied and those we verified from both USNM and UMSP collections, it is likely that he studied no more than two specimens identified as $E$. patchae, notably the type specimen in poor condition. Those conditions made revelation of significant differences between the two species difficult. 


\section{Molecular data in aphid diagnoses}

Aphids represent a relatively well-studied insect group mostly because of their economic importance. Molecular data are most often used in population genetics (Wongsa et al. 2017; Medina et al. 2017). They are used also in works linked with species recognition using barcodes because of their small size and their difficult systematics (Coeur d'acier et al. 2014; Lee et al. 2011). As in other animal groups, new aphid species can be discovered or confirmed using DNA analyses (Depa et al. 2012; Chen et al. 2015; Jiang et al. 2015). The present paper represents the first time that DNA sequence characters have been used in an aphid species diagnosis. Indeed, use of this kind of data and especially substitutions of nucleotides as characters is rare in animal diagnoses (Renner 2016), and rarer in insects. The precedent was established 8 years ago (Brower 2010). The International Code of Zoological Nomenclature does not explicitly recommend DNA sequence data to establish animal taxa, yet nor does it forbid it (ICZN 1999). Other kinds of non-morphological characters are commonly used in other groups. For example, songs or acoustic signals are used to differentiate species in several animal groups and can be considered good diagnostic characters in frogs (Brown and Richards 2008) or in Orthopteran insects (Hertach et al. 2015; Iorgu et al. 2017). In consequence, we judge that the absence, the presence, or the identity of a nucleotide or of a DNA sequence fragment are the molecular equivalent to the absence, the presence, or the shape of a seta, a puncture, or of any other morphological character. We thus support that this kind of DNA character can be used unambiguously in a diagnosis.

\section{Acknowledgments}

We are grateful to G. L. Miller (USDA Systematic Entomology Laboratory, Beltsville, MD), P. T. Oboyski (Essig Museum of Entomology, University of California, Berkeley, CA), and R. E. Thomson (University of Minnesota, St Paul, MN) for specimen loans. We extend our thanks to J. T. Sorensen for his advice and assistance in the field. We also thank the two reviewers, Susan Halbert and Roger Blackman, for the helpful comments on previous versions of the manuscript. Mariusz Kanturski gratefully acknowledges the Scholarship for Outstanding Young Scientists from the Ministry of Science and Higher Education of Poland (1165/E-340/STYP/12/2017).

\section{References}

Blackman RL, Eastop VF (2017) Aphids on the world's plants: An online identification and information guide. http://www.aphidinwordsplants.info/ [accessed on 2017-11-01]

Brower AV (2010) Alleviating the taxonomic impediment of DNA barcoding and setting a bad precedent: names for ten species of 'Astraptes fulgerator' (Lepidoptera: Hesperiidae: 
Eudaminae) with DNA-based diagnoses. Systematics and Biodiversity 8(4): 485-491. https://doi.org/10.1080/14772000.2010.534512

Brown RM, Richards SJ (2008) Two new frogs of the genus Platymantis (Anura: Ceratobatrachidae) from the Isabel Island group, Solomon Islands. Zootaxa 1888(1): 47-68.

Chen R, Jiang LY, Liu L, Liu QH, Wen J, Zhang RL, Li XY, Wang Y, Lei FM, Qiao GX (2013) The gnd gene of Buchnera as a new, effective DNA barcode for aphid identification. Systematic Entomology 38: 615-625. https://doi.org/10.1111/syen.12018

Chen J, Zhang B, Zhu X, Jiang L, Qiao GX (2015) Review of the aphid genus Aspidophorodon Verma, 1967 with descriptions of three new species from China (Hemiptera: Aphididae: Aphidinae). Zootaxa 4028(4): 551-576. https://doi.org/10.11646/zootaxa.4028.4.6

Cour d'acier A, Cruaud A, Artige E, Genson G, Clamens AL, Pierre É, Hudaverdian S, Simon JC, Jousselin E, Rasplus JY (2014) DNA barcoding and the associated PhylAphidB@se website for the identification of european aphids (Insecta: Hemiptera: Aphididae). PLoS ONE 9 (6): e97620.

Del Guercio G (1909) Intorno a due nuovi generi e a tre specie nuove di afidi di California. Rivista di Patologia Vegetale 3: 328-332.

Depa Ł, Mróz E, Szawaryn K (2012) Molecular identity of Stomaphis quercus (Hemiptera: Aphidoidea: Lachnidae) and description of a new species. European Journal of Entomology 109: 435-444. https://doi.org/10.14411/eje.2012.056

Essig EO (1909) Aphididae of southern California I. Pomona College Journal of Entomology 11-10. Favret C (2005) A new non-destructive DNA extraction and specimen clearing technique for aphids (Hemiptera). Proceedings of the Entomological Society of Washington 107: 469-470.

Gillette CP, Palmer MA (1924) New Colorado Lachnini. Annals of the Entomological Society of America 17(1): 1-57. https://doi.org/10.1093/aesa/17.1.1

Hebert PDN, Cywinska A, Ball SL, de Waard JR (2003a) Biological identifications through DNA barcodes. Proceedings of the Royal Society of London. Series B 270 (1512): 313321. https://doi.org/10.1098/rspb.2002.2218

Hebert PDN, Ratnasingham S, de Waard JR (2003b) Barcoding animal life: cytochrome $c$ oxidase subunit 1 divergences among closely related species. Proceedings of the Royal Society of London. Series B 270 (Suppl 1): S96-S99. https://doi.org/10.1098/rsbl.2003.0025

Hertach T, Trilar T, Wade EJ, Simon C, Nagel P (2015) Songs, genetics, and morphology: revealing the taxonomic units in the European Cicadetta cerdaniensis cicada group, with a description of new taxa (Hemiptera: Cicadidae). Zoological Journal of the Linnean Society 173(2): 320-351. https://doi.org/10.1111/zoj.12212

Hottes FC (1957) A synopsis of the genus Essigella (Aphidae). Proceedings of the Biological Society of Washington 70: 69-109.

Hottes FC (1958) A new species of Essigella from Oregon (Aphidae). Proceedings of the Biological Society of Washington 71: 155-156.

ICZN (1999). International Code of Zoological Nomenclature. 4th ed. London, UK: The International Trust for Zoological Nomenclature. 306 pp. http://iczn.org/iczn/index.jsp [accessed on 2017-11-01]

Iorgu IŞ, Iorgu EI, Szövényi G, Orci KM (2017) A new, morphologically cryptic bush-cricket discovered on the basis of its song in the Carpathian Mountains (Insecta, Orthoptera, Tettigoniidae). ZooKeys 680: 57-72. https://doi.org/10.3897/zookeys.680.12835 
Jiang L, Chen J, Guo K, Qiao GX (2015) Review of the genus Ceratovacuna (Hemiptera: Aphididae) with descriptions of five new species from China. Zootaxa 3986(1): 35-60. https://doi.org/10.11646/zootaxa.3986.1.2

Kanturski M, Karcz J, Wieczorek K (2015) Morphology of the European species of the aphid genus Eulachnus (Hemiptera: Aphididae: Lachninae) - a SEM comparative and integrative study. Micron 76: 23-36. https://doi.org/10.1016/j.micron.2015.05.004

Kimber W, Glatz R, Shaw S (2013) Introduction of the wasp Diaeretus essigellae, for biological control of Monterey Pine Aphid Essigella californica, in Australia. Final Report. Forest \& Wood Products Australia, Resources. Project Number PNC063-0607, Melbourne, Vic, 72 pp.

Lee W, Kim H, Lim J, Choi HR, Kim Y, Kim YS, Ji JY, Foottit RG, Lee S (2011) Barcoding aphids (Hemiptera: Aphididae) of the Korean Peninsula: updating the global data set. Molecular Ecology Resources 11: 32-37. https://doi.org/10.1111/j.1755-0998.2010.02877.x

Lee W, Lee Y, Kim H, Akimoto SI, Lee S (2014) Developing a new molecular marker for aphid species identification: Evaluation of eleven candidate genes with species-level sampling. Journal of Asia-Pacific Entomology 17: 617-627. https://doi.org/10.1016/j.aspen.2014.06.008

Lukhtanov VA, Dantchenko AV (2017) A new butterfly species from south Russia revealed through chromosomal and molecular analysis of the Polyommatus (Agrodiaetus) damonides complex (Lepidoptera, Lycaenidae). Comparative Cytogenetics 11(4): 769-795. https:// doi.org/10.3897/compcytogen.v11i4.20072

Medina RF, Armstrong SJ, Harrison K (2017) Genetic population structure of sugarcane aphid, Melanaphis sacchari, in sorghum, sugarcane, and Johnsongrass in the continental USA. Entomologia Experimentalis et Applicata 162(3): 358-365. https://doi.org/10.1111/eea.12547

Morinière J, Hendrich L, Balke M, Beermann AJ, König T, Hess M, Koch S, Müller R, Leese F, Hebert PDN, Hausmann A, Schubart CD, Haszprunar G (2017) A DNA barcode library for Germany's mayflies, stoneflies and caddisflies (Ephemeroptera, Plecoptera \& Trichoptera). Molecular Ecology Resources 17(6): 1293-1307. https://doi.org/10.1111/17550998.12683

Renner SS (2016) A return to Linnaeus's focus on diagnosis, not description: the use of DNA characters in the formal naming of species. Systematic biology 65(6): 1085-1095. https:// doi.org/10.1093/sysbio/syw032

Sorensen JT (1983) Cladistic and phenetic analysis of Essigella aphids: systematics and phylogeny in relation to their Pinaceae host plants (Homoptera: Aphididae, Lachninae). Ph.D. dissertation, University of California, Berkeley.

Sorensen JT (1988) Three new species of Essigella (Homoptera: Aphididae). Pan-Pacific Entomologist 64 (2): 115-125.

Sorensen JT (1994) A revision of the aphid genus Essigella (Homoptera: Aphididae: Lachninae): its ecological associations with, and evolution on, Pinaceae hosts. Pan-Pacific Entomologist 70(1): 1-102.

Théry T, Brockerhoff EG, Carnegie AJ, Chen R, Elms SR, Hullé M, Glatz R, Ortego J, Qiao GX, Turpeau É, Favret C (2017) EF-1a DNA Sequences Indicate Multiple origins of introduced populations of Essigella californica (Hemiptera: Aphididae). Journal of economic entomology 110(3): 1269-1274. https://doi.org/10.1093/jee/tox026 
Théry T, Kanturski M, Favret C (in press) Molecular phylogenetic analysis and species delimitation in the pine needle-feeding aphid genus Essigella (Hemiptera, Sternorrhyncha, Aphididae). Insect Systematics and Diversity.

Wilson HF (1919) Three new lachnids with comparative notes on three others (Homop.). Entomological News 30(1): 1-7.

Wongsa K, Duangphakdee O, Rattanawannee A (2017) Genetic structure of the Aphis craccivora (Hemiptera: Aphididae) from Thailand inferred from mitochondrial COI gene sequence. Journal of Insect Science 17(4): 84. https://doi.org/10.1093/jisesa/iex058 